\title{
ANALISIS KELAYAKAN FINANSIAL PRODUKSI SETUP BUAH NIPAH PADA SKALA INDUSTRI KECIL MENENGAH (IKM)
}

\author{
The Financial Feasibility Study of Nypa Punch Drink Production \\ on Small and Medium Sized Enterprise
}

\author{
Ika Atsari Dewi ${ }^{1,2 *}$, Usman Effendi ${ }^{1}$, Susinggih Wijana ${ }^{1,2}$, Dwi Novanda Sari ${ }^{1}$ \\ 1Jurusan Teknologi Industri Pertanian - Fakultas Teknologi Pertanian - Universitas Brawijaya \\ Jl. Veteran- Malang 65145 \\ ${ }^{2}$ Kelompok Kajian Agroindustri Palma - Universitas Brawijaya \\ Jl. Veteran - Malang 65145 \\ Penulis Korespondensi, email : ikaatsaridewi@ub.ac.id
}

Disubmit: 6 November 2017 Direvisi: 19 Februari 2019 Diterima: 15 Maret 2019

\begin{abstract}
ABSTRAK
Tanaman nipah memiliki banyak manfaat dan berpotensi untuk dikembangkan. Diversifikasi produk berupa setup buah nipah dapat dijadikan salah satu alternatif untuk memaksimalkan peningkatan nilai ekonomis tanaman nipah. Penelitian ini bertujuan mengetahui kelayakan finansial produksi setup buah nipah pada skala Industri Kecil dan Menengah (IKM). Analisis kelayakan finansial yang dilakukan terdiri dari perhitungan Harga Pokok Produksi (HPP), Net Present Value (NPV), Internal Rate of Return (IRR), efisiensi usaha (R/C ratio), Break Event Point (BEP), dan Payback Period (PP). Harga Pokok Produksi (HPP) setup buah nipah sebesar Rp 5.192 dengan harga jual Rp 7.300 per kemasan. Net Present Value (NPV) sebesar Rp 4.408.799.785. Internal Rate of Return (IRR) sebesar 10.44\%. Efisiensi usaha (R/C ratio) sebesar 1.44. Untuk mencapai Break Even Point (BEP), tingkat penjualan harus sebesar 797851 cup atau senilai Rp 5.800.371.040, serta payback period selama 1 tahun 8 bulan. Berdasarkan perhitungan finansial yang dilakukan, disimpulkan bahwa produksi setup buah nipah layak dilakukan.
\end{abstract}

Kata kunci: Analisa Kelayakan Finansial; Buah Nipah; Setup

\begin{abstract}
The availability of nypa fruit in Indonesia has the potential to be developed. In order to maximize the increasing economic value of nypa plants, it is necessary to make a diversification product with high economic value, such as the production of nypa punch drink. The aim of the research is to determine the financial feasibility of nypa punch drink production on Small and Medium Scale Enterprise (SME). Financial feasibility analysis include Cost of Goods Manufactured (CoGM), Net Present Value (NPV), Internal Rate of Return (IRR), business efficiency (R/C ratio), Break Event Point (BEP), and Payback Period (PP). The Cost of Goods Manufactured (CoGM) of nypa punch drink is Rp 5.192 with the selling price of Rp 7.300 per cup. Net Present Value (NPV) is Rp 4.408.799.785. Internal Rate of Return (IRR) is $10.44 \%$. Business efficiency (R/C ratio) is 1.44. Break Even Point (BEP) is achieved at the selling rate of 797.851 cups or equivalent to Rp 5.800.371.040. and the Payback Period is about 1 year and 8 months. Based on the financial calculations performed, it can be concluded that the production of nypa punch drink is feasible.
\end{abstract}

Keyword : Feasibility Study; Fruit Drinks; Nypa fruit 


\section{PENDAHULUAN}

Potensi tanaman nipah begitu besar di Indonesia. Total populasi nipah di Indonesia diperkirakan mencapai 5.6 milyar pohon. Nilai ini diestimasikan dari luas tanaman nipah di seluruh Indonesia yang diperkirakan mencapai 700000 ha dengan rerata populasi pohon 8000/ha (Baharuddin dan Taskirawati, 2009). Di Provinsi Jawa Timur, sentra tanaman nipah terdapat di Pulau Bawean, Kabupaten Gresik, Jawa Timur dimana terdapat 280 ha tanaman nipah. Luasan tersebut cukup potensial untuk dikembangkan menjadi agroindustri berbasis nipah, dan mampu menyerap lapangan kerja sebagai penyadap nira sebanyak 1120 orang, diutamakan bagi masyarakat miskin serta tanaman nipah mampu menjaga ekosistem pantai/pesisir Pulau Bawean (Wijana, 2011).

Pemanfaatan buah nipah yang telah dilakukan masih terbatas, diantaranya dalam bentuk manisan basah (Wahyudi, 2011), tepung nipah (Heriyanto et al., 2011), dan ekstender papan partikel (Sari et al., 2008). Diversifikasi produk diperlukan untuk meningkatan nilai ekonomis tanaman nipah, salah satunya adalah produksi setup buah nipah, disamping itu prospek pengembangan buah-buahan cukup baik karena permintaan pasar luar negeri terus meningkat. Setup buah nipah yang dikembangkan merupakan produk olahan buah nipah yang diawetkan dalam kemasan, dengan menggunakan air nira dari sadapan tandan bunga nipah sehingga dihasilkan produk dengan kandungan yang berkualitas.

Pengembangan industri produk setup buah nipah memerlukan analisis kelayakan untuk memberikan masukan terhadap strategi pengembangan produk baru. Salah satunya adalah analisis kelayakan finansial. Penetapan kelayakan suatu usaha perlu dilakukan pengujian kelayakan (Nurlaila, 2014). Studi kelayakan mengkaji secara sistematis rencana suatu proyek baru maupun pengembangan usaha yang sudah ada. Studi kelayakan usaha dapat membantu para pengusaha, pemilik modal dan pihak terkait dalam mengambil keputusan kelayakan usaha patut dilaksanakan atau tidak (Ibrahim, 2009; Karpyn et al., 2018). Aspek finansial dapat mengetahui apakah keuntungan yang diperoleh layak dan mampu untuk memenuhi kewajiban finansialnya.
Tujuan penelitian ini adalah mengetahui kelayakan finansial produksi setup buah nipah pada skala Industri Kecil dan Menengah (IKM). Manfaat penelitian adalah memberikan informasi tentang kelayakan finansial produksi setup buah nipah, selain itu merupakan salah satu referensi dalam implementasi pendirian industri setup buah nipah. Penelitian ini merupakan bagian dari payung penelitian pengembangan teknologi diversifikasi produk olahan nipah menjadi aneka produk pangan dan kertas seni.

\section{METODE}

Penelitian dilakukan di Laboratorium Teknologi Agrokimia dan Laboratorium Komputasi dan Analisis Sistem Universitas Brawijaya, serta pengambilan data di Kabupaten Malang dan Pulau Bawean Kabupaten Gresik Provinsi Jawa Timur. Pengumpulan data primer dan sekunder dilakukan melalui survei, wawancara, dan studi literatur. Pengolahan data dilakukan dengan melakukan perhitungan aspek finansial yang dianalisis yang meliputi perhitungan Harga Pokok Produksi (HPP), Net Present Value (NPV), Internal Rate of Return (IRR), efisiensi usaha (R/C ratio), Break Event Point (BEP), dan Payback Period (PP). Biaya-biaya yang dikalkulasi dalam analisis finansial dalam penelitian ini antara lain biaya bahan baku dan bahan pengemas, biaya kebutuhan utilitas, modal tetap, biaya penyusutan, biaya tetap dan biaya tidak tetap. Analisis kelayakan finansial yang dilakukan ditunjukkan pada perhitungan Harga Pokok Produksi (HPP), Net Present Value (NPV), Internal Rate of Return (IRR), efisiensi usaha (R/C ratio), Break Event Point (BEP), dan Payback Period (PP).

\section{Harga Pokok Produksi (HPP)}

Perhitungan HPP menggunakan rumus yang ditunjukkan pada Persamaan 1 (Idham et al., 2010).

$\mathrm{HPP}=\frac{\text { total biaya selama } 1 \text { tahun }}{\text { jumlah produksi selama } 1 \text { tahun }}$

\section{Net Present Value (NPV)}

Rumus yang digunakan untuk menghitung NPV ditunjukkan pada Persamaan 2. 
$\mathrm{NPV}=\sum_{i=1}^{n} \frac{N B i}{(1+i)^{n}}$

Keterangan :

$\mathrm{NB}=$ Net Benefit (benefit cost)

$i=$ discount factor

$n$ = waktu (tahun)

Jika NPV lebih besar dari 0 (nol) maka dikatakan usaha tersebut layak (feasible), demikian berlaku sebaliknya.

\section{Internal Rate of Return (IRR)}

Formulasi IRR dapat dirumuskan seperti yang ditunjukkan pada Persamaan 3 (Astanu et al., 2013).

$\mathrm{IRR}=\mathrm{i} 1+\frac{N P V 1}{N P V 1-N P V 2} \times(\mathrm{i} 2-\mathrm{i} 1)$

Keterangan:

\begin{tabular}{|c|c|}
\hline NPV 1 & $=$ NPV yang bernilai positif \\
\hline NPV 2 & $=$ NPV yang bernilai negatif \\
\hline i1 & $\begin{aligned}= & \text { discount rate yang } \\
& \text { menghasilkan NPV positif }\end{aligned}$ \\
\hline i2 & $\begin{aligned}= & \text { discount rate yang } \\
& \text { menghasilkan NPV negatif }\end{aligned}$ \\
\hline
\end{tabular}

Apabila hasil perhitungan IRR lebih besar dari tingkat suku bunga maka usaha tersebut dikatakan layak untuk dikembangkan, namun bila sama dengan tingkat suku bunga berarti usaha tersebut berada dalam keadaan BEP, dan bila besarnya dibawah tingkat suku bunga maka usaha tersebut dikatakan tidak layak untuk dikembangkan.

\section{Efisiensi usaha (R/C ratio)}

Rumus efisiensi usaha $\mathrm{R} / \mathrm{C}$ oditunjukkan pada Persamaan 4.

$\mathrm{R} / \mathrm{C}=\frac{T R}{T C}$

dengan:

$\mathrm{TR}=\mathrm{P} \times \mathrm{Q}$

$\mathrm{TC}=\mathrm{TFC}+\mathrm{TVC}$

Keterangan:

$\mathrm{TR}=$ Total Revenue (total seluruh penerimaan yang didapat)

$\mathrm{P}=$ Price (Harga)

$\mathrm{Q}=$ Quantity (jumlah unit)

$\mathrm{TC}=$ Total Cost (jumlah seluruh biaya yang dikeluarkan)

Adapun kriteria pengujian dengan menggunakan $\mathrm{R} / \mathrm{C}$ ratio adalah $\mathrm{R} / \mathrm{C}<1$ usaha tidak efisien atau merugikan; $\mathrm{R} / \mathrm{C}=1$ usaha tidak menguntungkan atau tidak merugikan; serta R/C > 1 usaha efisien atau menguntungkan.

\section{Break Event Point (BEP)}

BEP atau titik impas adalah titik dimana total biaya produksi sama dengan pendapatan. Perhitungan BEP menggunakan Persamaan 7 (Astanu et al., 2013):

$\mathrm{BEP}(\mathrm{Q})=\frac{F C}{P-V C}$

$B E P(R P)=\frac{F C}{1-V C / P}$

Keterangan :

$\mathrm{Q}=$ jumlah kuantitas (unit) produk yang

dihasilkan \& dijual

$\mathrm{FC}=$ Fixed Cost (biaya tetap)

$\mathrm{VC}=$ Variable Cost (biaya tidak tetap)

$\mathrm{P}$ = harga jual per unit

$S$ = volume penjualan

\section{Payback Period (PP)}

Formulasi model metode ini ditunjukkan pada Persamaan 9 (Astanu et al., 2013):

Payback period $=\frac{1}{A_{b}} \times 1$ tahun

Keterangan :

I = jumlah invest asi awal (modal investasi dan modal kerja)

$A_{b}=$ rata-rata penerimaan bersih

$$
\mathrm{PP}=\frac{\text { investasi awal }}{\text { pendapatan bersih }} \times 1 \text { tahun }
$$

\section{HASIL DAN PEMBAHASAN}

Hal yang termasuk dalam modal tetap antara lain berupa biaya untuk peralatan produksi, peralatan kantor, serta biaya lain-lain. Biaya total yang harus dikeluarkan untuk pembelian peralatan produksi yaitu sebesar Rp 69.963.000. Pembelian peralatan kantor seperti pembelian alat tulis dan meja kursi membutuhkan biaya sebesar Rp 4.587.300, biaya alat transportasi sebesar Rp 2.004.000.000 dan biaya lain-lain hingga total modal tetap dalam pembuatan setup buah nipah yaitu sebesar Rp 3.458.374.990. 
Nilai dari suatu aktiva beserta manfaatnya akan mengalami penurunan seiring waktu, sehingga Penyusutan atau yang juga disebut depresiasi perlu dihitung. Depresiasi merupakan alokasi jumlah suatu aktiva yang dapat disusutkan selama waktu yang diestimasi. Perhitungan depresiasi dalam penelitian ini dilakukan dengan menggunakan metode garis lurus atau straight line dimana perhitungannya meratakan biaya selama periode (Harding et al., 2007; Triswiyanti, 2014; Jennergen, 2018). Biaya penyusutan yang dihitung meliputi peralatan produksi, peralatan kantor dan alat transportasi dengan total biaya penyusutan sebesar $\mathrm{Rp}$ 288.723.250. Modal kerja yang dikeluarkan untuk produksi setup buah nipah per bulan sebesar Rp 6.944.237.384.

Total investasi awal merupakan jumlah dari modal tetap ditambahkan dengan modal kerja pada bulan pertama proses produksi berlangsung, sehingga nilai total investasi awal produksi setup buah nipah sebesar Rp 4.037.061.439. Total biaya tetap per tahun yang harus dikeluarkan yaitu sebesar Rp 3.458.374.990, meliputi biaya gaji tenaga kerja, pemeliharaan alat dan bangunan, serta biaya penyusutan (depresiasi). Biaya tidak tetap yang harus dikeluarkan berjumlah Rp 4.497.459.000 per tahun, meliputi biaya pembelian bahan baku dan bahan pembantu, bahan pengemas, serta biaya utilitas. Total biaya produksi per tahun diperoleh dari penjumlahan biaya tetap dan tidak tetap per tahun yaitu sebesar Rp 7.955.833.990.

\section{Harga Pokok Produksi (HPP)}

Harga pokok produksi diperoleh dengan menjumlahkan total biaya selama

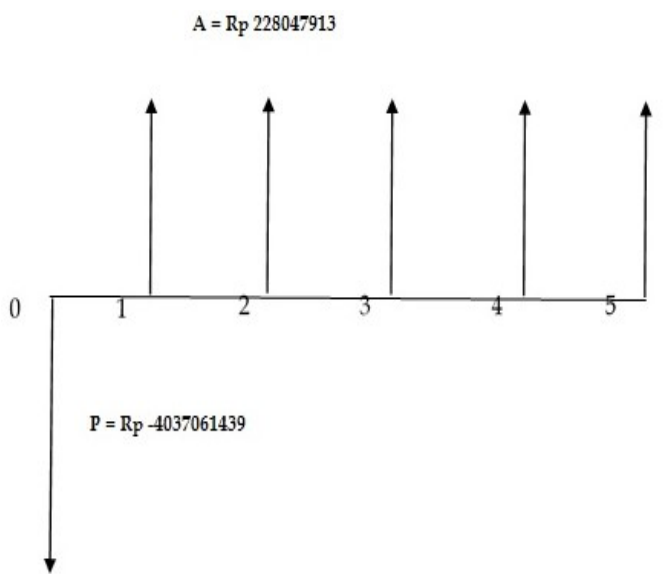

Gambar 1. Diagram cash flow setahun dibagi dengan jumlah produksi selama setahun. Jumlah produk yang dihasilkan selama setahun sebanyak 1532154 buah, menghasilkan HPP sebesar Rp 5.192.581. Harga pokok produksi tersebut belum termasuk mark up sebesar $40 \%$. Besarnya mark up untuk produk non pangan berbeda-beda tergantung dari tingkatannya. Jika penjualan dilakukan pada tingkat produsen langsung ke konsumen, maka mark up yang diberikan sebesar 20\%. Jika penjualannya melalui agen sampai ke pengecer, nilai mark up bertambah menjadi $40 \%$, sementara bila produk tersebut dijual pengecer hingga ke konsumen akhir maka mark up meningkat menjadi $70 \%$. Biaya dan pendapatan per tahun dapat dilihat pada Tabel 1. Setelah ditambahkan dengan mark up, didapatkan harga jual tiap produknya sebesar Rp 7.300. Harga jual produk setup buah nipah ini masih bersaing dengan harga produk setup buah kemasan yang komersial saat ini yang berharga $\mathrm{Rp} 7.000$ dari pabrik yang belum dikenal masyarakat dan produk komersial dari merek yang sudah terkenal dengan harga Rp 42.000 per 250 g cup, sehingga bisa dikatakan produk setup buah nipah ini layak untuk dijual di pasaran.

\section{Break Event Point (BEP)}

Break Event Point (BEP) adalah volume penjualan dimana penghasilan atas penjualan tetap sama dengan total biaya produksi sehingga perusahaan tidak mendapatkan keuntungan ataupun mengalami kerugian. Jumlah volume penjualan minimum berdasarkan perhitungan $\mathrm{BEP}(\mathrm{Q})$ sebanyak 797851 cup, sementara kalkulasi BEP sebesar Rp 5.800.371.040. Hal ini menginformasikan bahwa titik impas terjadi jika 797851 cup setup buah nipah telah terjual dengan Biaya penjualan sebesar Rp 5.800.371.040.

\section{Efisiensi Usaha (R/C Ratio)}

Berdasarkan hasil kalkulasi diketahui total penerimaan sebesar Rp 7.955.833.990. Biaya pengeluaran terdiri dari biaya tetap selama setahun (fixed cost) sebesar $\mathrm{Rp}$ 3.458.374.990 dan biaya tidak tetap selama setahun (variable cost) sebesar Rp 4.497.459.000. Jumlah total dari biaya pengeluaran sebesar Rp 7.955.833.990. Hasil perhitungan R/C ratio sebesar 1.44. Karena nilainya lebih dari 1, maka produksi setup buah nipah dapat dikatakan layak.

Kriteria yang telah ditentukan adalah $\mathrm{R} / \mathrm{C}$ ratio $<1$ maka perusahaan akan rugi. 
Tabel 1. Biaya per tahun

\begin{tabular}{clr}
\hline No & Jenis & Jumlah (Rp) \\
\hline 1 & Biaya tetap selama setahun (FC) & 3.458 .374 .990 \\
2 & Biaya tidak tetap selama setahun (VC) & 4.497 .459 .000 \\
3 & Total Biaya selama setahun & $\mathbf{7 . 9 5 5 . 8 3 3 . 9 9 0}$ \\
4 & Jumlah produksi selama setahun & 1.532 .154 \\
5 & Biaya Tidak tetap per unit (VC per unit) & 2.936 \\
\hline
\end{tabular}

Tabel 2. Tabel NPV

\begin{tabular}{crcr}
\hline Tahun & Cash Flow $(\mathrm{Rp})$ & DF 60\% & \multicolumn{1}{c}{ Present Value $(\mathbf{R p})$} \\
\hline 0 & -4.037 .061 .439 & & -4.037 .061 .439 \\
1 & 2.228 .047 .913 & 09091 & 2.025 .518 .358 \\
2 & 2.228 .047 .913 & 0.8264 & 1.841 .258 .795 \\
3 & 2.228 .047 .913 & 0.7513 & 1.673 .932 .397 \\
4 & 2.228 .047 .913 & 0.683 & 1.521 .756 .725 \\
5 & 2.228 .047 .913 & 0.6209 & 1.383 .394 .949
\end{tabular}

Tabel 3. Tabel NPV positif

\begin{tabular}{crrr}
\hline Tahun & Cash Flow $(\mathbf{R p})$ & DF 10\% & Present Value (Rp) \\
\hline 0 & -403.7061 .439 & & -4.037 .061 .439 \\
1 & 2.228 .047 .913 & 0.9091 & 2.025 .518 .358 \\
2 & 2.228 .047 .913 & 0.8264 & 1.841 .258 .795 \\
3 & 2.228 .047 .913 & 0.7513 & 1.673 .932 .397 \\
4 & 2.228 .047 .913 & 0.683 & 1.521 .756 .725 \\
5 & 2.228 .047 .913 & 0.6209 & 1.383 .394 .949 \\
& & $\mathrm{NPV}=$ & 4.408 .799 .785 \\
\hline
\end{tabular}

Tabel 4. Tabel NPV negatif

Tahun

0

1

2

3

4

5

\section{Cash Flow (Rp)}

$-4.037 .061 .439$

2.228.047.913

2.228.047.913

2.228.047.913

2.228.047.913

2.228.047.913
DF 60\%

Present Value (Rp)

$-4.037 .061 .439$

1.392.529.946

$870.275 .514,8$

$543.866 .495,6$

$340.000 .111,5$

212.555.770,9

$-677.833 .600,2$ 
Jika $\mathrm{R} / \mathrm{C}$ ratio $=1$ maka perusahaan impas, dan apabila $\mathrm{R} / \mathrm{C}$ ratio $>1$ maka perusahaan akan laba. Semakin besar nilai $\mathrm{R} / \mathrm{C}$ ratio maka tingkat keuntungan yang akan diperoleh perusahaanjuga semakin besar (Soekartawi,1995).

\section{Net Present Value (NPV)}

Net Present Value (NPV) menghitung nilai bersih pada waktu sekarang dengan menggunakan tingkat suku bunga (discount factor) yang berlaku. Tingkat suku bunga yaitu $10 \%$ per tahun, sehingga dalam perhitungan NPV setup buah nipah, tingkat suku bunga yang digunakan yaitu sebesar $10 \%$ selama 5 tahun produksi. Perhitungan proyeksi arus kas menggunakan estimasi discount factors (DF) sebesar 60\% (BI rate tahun 2012 $6.50 \%$ ). Perhitungan DF dilakukan untuk mengestimasikan suatu jumlah nilai dimasa yang akan datang (future value) agar menjadi nilai saat ini (present value). Caranya dengan mengalikan DF, yaitu bilangan kurang dari 1 dengan future value.

Menurut perhitungan proyeksi arus kas (cash flow) dengan umur proyek 5 tahun, cash flow yang diperoleh adalah sebesar Rp 2228047913 pada tiap tahunnya. Perhitungan NPV dapat dilihat berdasarkan Tabel 2, sedangkan diagram cash flow dapat dilihat pada Gambar 1.

Berdasarkan perhitungan NPV tersebut, didapatkan nilai akhir sebesar Rp 4.408.799.785. Nilai hasil perhitungan NPV tersebut bernilai positif. Usulan proyek yang memiliki nilai NPV positif (lebih besar dari nol) dapat diterima dan apabila NPVnya negatif, maka usulan proyek tersebut akan ditolak (Oehmke, 2000; Soeharto, 2002; Žižlavský, 2014; Fleten et al., 2016).

\section{Internal Rate of Return (IRR)}

Internal Rate of Return (IRR) digunakan untuk menghitung tingkat suku bunga yang menyamakan nilai sekarang investasi dengan nilai sekarang penerimaan kas-kas bersih di masa yang akan datang. IRR dihitung dengan cara interpolasi. Nilai IRR yang diperoleh sebesar $10.44 \%$. Perhitungan tersebut menunjukkan bahwa IRR $10.44 \%$ > DF 10\%. Jika nilai IRR lebih besar dari DF maka usaha dapat dikatakan layak (Jumingan, 2009; Bejbl et al., 2014; Santandrea et al., 2017). Nilai IRR dapat diperoleh berdasarkan perhitungan persentase discount factor yang membentuk NPV positif dan NPV negatif. Tabel NPV positif dapat dilihat pada Tabel 3, sedangkan Tabel NPV negatif dapat dilihat pada Tabel 4 .

\section{Payback Period (PP)}

Untuk mengetahui barapa lama suatu usaha dapat mengembalikan investasi dapat dilakukan dengan menghitung payback period (PP). Nilai payback period (PP) hasil perhitungan menunjukkan usaha produksi setup buah nipah dicapai pada 1 tahun 8 bulan. Suatu proyek dikatakan layak apabila waktu PP lebih singkat dari pada umur proyek yang direncanakan (Pujawan, 2004; Heysel dan Filion, 2014; Wang et al., 2015; Nguyen et al., 2017). Berdasarkan perhitungan dapat dilihat lama pengembalian investasi usaha produksi setup buah nipah lebih cepat dibandingkan dengan umur ekonomis proyek yaitu 5 tahun.

\section{SIMPULAN}

Hasil perhitungan finansial memperlihatkan bahwa Harga Pokok Produksi (HPP) setup buah nipah sebesar Rp 5.192 dengan harga jual Rp 7.300 per cup. Break Even Point tercapai pada tingkat penjualan 797851 cup atau senilai Rp 580.0371.040. Efisiensi usaha (R/C ratio) sebesar 1.44. Net Present Value (NPV) sebesar Rp 4.408.799.785. Internal Rate of Return (IRR) sebesar 10.44\% serta payback period selama 1 tahun 9 bulan. Dari hasil perhitungan finansial yang dilakukan, dapat disimpulkan bahwa produksi setup buah nipah layak dilakukan.

\section{UCAPAN TERIMA KASIH}

Terima kasih disampaikan kepada Badan Penelitian dan Pengembangan Provinsi Jawa Timur atas pembiayaan yang diberikan. Penelitian ini merupakan rangkaian penelitian dengan judul besar "Inovasi Teknologi Pengembangan Olahan Gula Nipah Menjadi Aneka Pangan dan Kertas Seni". 


\section{DAFTAR PUSTAKA}

Astanu, D, -A., Ismono R, -H., Rosanti, -N., 2013. Analisis kelayakan finansial budidaya intensif tanaman pala di kecamatan gisting kabupaten tanggamus. Jurnal Ilmu-Ilmu Agribisnis. 1, 218-225. http://dx.doi.org/10.23960/ jiia.v1i3.218-225

Baharuddin, Taskirawati, -I., 2009. Hasil Hutan Bukan Kayu. Universitas Hasanuddin. Kalimantan

Bejbl, -J., Bemš, -J., Králík, -T., Starý, -O., Vastl, -J., 2014. New approach to brown coal pricing using internal rate of return methodology. Applied Energy. 133, 289297. https://doi.org/10.1016/j.apenergy.2014.07.082

Fleten, S, -E., Linnerud, -K., Molnár, -P., Nygaard, M, -T., 2016. Green electricity investment timing in practice: Real options or net present value?. Energy. 116, 498-506. https://doi. org/10.1016/j.energy.2016.09.114

Harding, J, -P., Rosenthal, S, -S., Sirmans, C, -F., 2007. Depreciation of housing capital, maintenance, and house price inflation: estimates from a repeat sales model. Journal of Urban Economics. 61, 193-217. https://doi.org/10.1016/j. jue.2006.07.007

Heriyanto, N, -M, Subiandono, -E., Karlina, -E., 2011. Potensi dan Sebaran Nipah (Nypa fruticans (Thunb.) Wurmb) sebagai sumberdaya pangan. Jurnal Penelitian Hutan dan Konservasi Pangan, 8, 327-335. https:/ / doi.org/10.20886/ jphka.2011.8.4.327-335

Heysel, C, -S., Filion, Y, -R., 2014. Estimating the payback period of in-line micro turbines with analytical probabilistic models. Procedia Engineering. 70, 815822. https://doi.org/10.1016/j.proeng.2014.02.089

Ibrahim, Y. 2009. Studi Kelayakan Bisnis. PT Rineka Cipta. Jakarta

Idham, -A., Lestari, -T. Adriani, -D. 2010. Analisis finansial sistem usaha tani terpadu (integrated farming system) berbasis ternak sapi di kabupaten oganilir. Jurnal Pembangunan Manusia. 6.

Jennergren, L, -P., 2018. A note on the linear and annuity class of depreciation methods. International Journal of Production Economics, 204, 123-134. https://doi. org/10.1016/j.ijpe.2018.05.004

Jumingan. 2009. Studi Kelayakan Bisnis. PT Rineka Cipta, Jakarta

Karpyn, -A., DeWeese, R, -S., Pelletier, J, -E., Laska, M, -N., Ohri-Vachaspati, -P., Deahl-Greenlaw, -A., Ughwanogho, -O., Pitts, S, B, -C., 2018. Examining the Feasibility of healthy minimum stocking standards for small food stores. Journal of the Academy of Nutrition and Dietetics. 118, 1655-1663. https://doi. org/10.1016/j.jand.2017.12.006

Nguyen, T, -H., Williams, -S., Paustian, -K., 2017. Impact of ecosystem carbon stock change on greenhouse gas emissions and carbon payback periods of cassava-based ethanol in Vietnam. Biomass and Bioenergy. 100, 126-137. https://doi.org/10.1016/j.biombioe.2017.02.009

Nurlaila, N. 2014. Analisis Distribusi dan Keuntungan Industri Rumah Tangga Tempe di Kecamatan Telaga. Skripsi. Universitas Gorontalo.

Oehmke, J, -F., 2000. Anomalies in net present value calculations. Economics Letters. 67, 349-351. https://doi.org/10.1016/ S0165-1765(99)00271-2

Pujawan, IN. 2004. Ekonomi Teknik. Guna Widya, Surabaya

Santandrea, -M., Sironi, -A., Grassi, -L., Giorgino, -M., 2017. Concentration risk and internal rate of return: Evidence from the infrastructure equity market. International Journal of Project Management. 35, 241-251. https://doi. org/10.1016/j.ijproman.2016.10.011

Sari, N, -M, Rosidah, Rahman, M, -Y. 2008. Penggunaan tepung buah nipah (Nypa fructicans Wurmb.) sebagai ekstender pada perekat urea formaldehid untuk papan partikel. Jurnal Ilmu Kehutanan, 2, 48-54. https://doi.org/10.22146/ jik.1536

Soeharto, I. 2002. Manajemen Proyek. Erlangga, Jakarta

Soekartawi. 1995. Prinsip Dasar Manajemen Pemasaran Hasil-Hasil Pertanian, Teori dan Aplikasinya. Raja Grafindo Persada, Jakarta

Triswiyanti. 2014. Studi Kelayakan Bisnis. Gramedia Pustaka Utama, Jakarta

Wahyudi, R. 2011. Kajian Pembuatan Manisan Basah dari Buah Nipah (Nypa fructicans Wurmb.). Skripsi. Universitas Syiah Kuala Darussalam. Banda Aceh. 
Jurnal Teknologi Pertanian Vol. 20 No. 1 [April 2019] 25-32

Analisis Kelayakan Finansial Produksi Setup Buah Nipah [Dewi dkk]

Wang, X, -Q., Li, X, -P., Li, Y, -R., Wu, C, -M., 2015. Payback period estimation and parameter optimization of subcritical organic rankine cycle system for waste heat recovery. Energy. 88, 734745. https://doi.org/10.1016/j.energy.2015.05.095

Wijana, S. 2011. Identifikasi Potensi Tanaman Nipah (Nypa fructican) Sebagai Sumber
Gula Alternatif Di Jawa Timur. In Proceeding Seminar Nasional Asosiasi Profesi Teknologi Agroindustri. Yogyakarta Žižlavský, -O., 2014. Net present value approach: method for economic assessment of innovation projects. Procedia - Social and Behavioral Sciences. 156, 506-512. https://doi.org/10.1016/j.sbspro.2014.11.230 